\title{
Thermal Conversion of Pine Wood and Kinetic Analysis under Oxidative and Non-Oxidative Environments at Low Heating Rate ${ }^{\dagger}$
}

\author{
Lelis Gonzaga Fraga ${ }^{1}$, João Silva ${ }^{2,3, *}$, Senhorinha Teixeira ${ }^{3}$, Delfim Soares ${ }^{4}$, Manuel Ferreira ${ }^{2}$ \\ and José Teixeira ${ }^{2}$ \\ 1 Department of Mechanical Engineering, Faculty of Engineering, Science and Technology, \\ Universidade Nacional Timor Lorosa'e, P.O. Box 317, Díli, Timor-Leste; lelisfraga@hotmail.com \\ 2 MEtRICs Research Centre, University of Minho, 4800-058 Guimarães, Portugal; ef@dem.uminho.pt (M.F.); \\ jt@dem.uminho.pt (J.T.) \\ 3 ALGORITMI Research Centre, University of Minho, 4800-058 Guimarães, Portugal; st@dps.uminho.pt \\ 4 CMEMS Research Centre, University of Minho, 4800-058 Guimarães, Portugal; dsoares@dem.uminho.pt \\ * Correspondence: js@dem.uminho.pt \\ + Presented at the First World Energies Forum, 14 September-05 October 2020; Available online: \\ https://wef.sciforum.net/.
}

Published: 11 September 2020

\begin{abstract}
Atmosphere is one of the most significant factors in the thermal decomposition of biomass. In domestic or industrial biomass boilers, ambient oxygen concentration varies through time, which means that the reaction will change from pyrolysis to combustion. In this way, to analyze and compare each thermochemical conversion process, a simple analytical method, the non-isothermal thermogravimetric analysis, is carried out under oxidative (air) and non-oxidative (argon) environments at $10^{\circ} \mathrm{C} / \mathrm{min}$ and as a function of different flow rates ( 2 to $150 \mathrm{~mL} / \mathrm{min}$ ). Additionally, this work was complemented by a kinetic analysis considering a first-order reaction to each conversion stage and using the Coats-Redfern method. The effect of the atmosphere on the thermal decomposition behavior was evident. It was observed that the thermal decomposition of pine wood particles varied from three to two stages when the oxidative or inert atmosphere was applied. The presence of oxygen changes the mass loss curve mainly at high temperature, around $350{ }^{\circ} \mathrm{C}$, where char reacts with oxygen. The maximum mass loss rate from experiments with the oxidative atmosphere is $15 \%$ higher than in an inert atmosphere, the average char combustion rate is approximately 5 times higher and the heat released reaches levels 3.44 times higher than in an inert atmosphere. Ignition and combustion indexes were also defined, and results revealed that particles are ignited faster under oxidative atmosphere and that, on average, the combustion index is 1.7 times higher, which reinforces the more vigorous way that the samples are burned and how char is burned out faster in the experiments with air. Regarding the kinetics analysis, higher activation energies, and consequently, lower reactivity was obtained under the oxidative atmosphere for the second stage $(\sim 125 \mathrm{~kJ} / \mathrm{mol})$ and under the inert atmosphere for the third thermal conversion stage $(\sim 190 \mathrm{~kJ} / \mathrm{mol})$.
\end{abstract}

Keywords: biomass; thermal degradation; thermogravimetric analysis; kinetics

\section{Introduction}

Due to increasing concerns about the limited availability of fossil fuels and pollutant emissions by conventional systems, sustainable heat and power generation from biomass are of great interest for scientific and industrial communities given its potential as an alternative and renewable energy 
source [1]. Therefore, it is important to understand the physical and chemical processes involved in biomass combustion, which is the main conversion process used in industrial boilers to produce energy [2]. In this thermochemical conversion process, the main step is devolatilization and its knowledge as the knowledge of its kinetics can help provide a better understanding of the design and optimization of biomass combustion systems [3].

To understand this phenomenon, the thermogravimetric analysis (TGA) technique is widely applied to study the thermal degradation of biomass samples and in kinetic studies, due to the ease in sample weight loss and temperature profile along the time [4,5]. In this way, the different stages can easily be distinguished in a TGA curve. Furthermore, the characteristic temperatures (i.e., onset, peak and offset temperatures of the maximum weight loss rate) are important parameters to establish the residence time desired for the biomass in the combustion chamber and can be obtained by the differential thermogravimetric data.

These results depend on several factors, but studies with a low heating rate are able to determine the temperatures from which the pyrolytic reactions start more precisely and to avoid transport effects [6]. In addition to factors such as final temperature and heating rate, first stated by Williams et al. [7] as parameters that influence thermal decomposition and the composition of the final products, the atmosphere is also a factor that influences the thermal behavior of biomass.

In a real application of biomass combustion to produce power, for instance in an industrial gratefired boiler, the temperature of the biomass increases and volatiles are released quickly due to the high heating rate that they are exposed to (around 1 to $100 \mathrm{~K} / \mathrm{s}$ ) [8]. This fast reaction results in insufficient air to diffuse into biomass, and ambient oxygen concentration varies as time passes, which means that the reaction will change from pyrolysis to combustion [9]. Nevertheless, although modern boilers operate in oxygen-limited combustion under low primary air flow rate, it is important to point out that most of the time this equipment operates in reaction-limited combustion due to high primary air supply [10]. However, most of the studies in the literature have investigated the pyrolysis using inert atmospheres [11-23]. This is due the fact that pyrolysis is the first process in thermochemical processes such as combustion and gasification [24].

However, few results have been generated from experiments with air [25-31]. Shen et al. [32] and Anca-Couce et al. [33] reported that the presence of oxygen enhances biomass decomposition and promotes char combustion. Furthermore, the kinetic parameters resulting from oxidative atmospheres differ significantly from experiments in the absence of oxygen [33]. Therefore, to simulate combustion conditions, it is important to study thermal behavior and kinetics in an oxygen atmosphere. In this way, in order to understand these differences, the influence of both oxidative and non-oxidative atmospheres on the biomass thermal conversion have been studied by different authors [32,34-36]. Munir et al. [34] analyze the thermal characteristics of four waste biomass materials, and the results showed that is a complex phenomenon due to different microstructural and elemental characteristics along with the type of atmosphere. The authors found that the weight loss rate in an inert atmosphere was slower and that its reactivity is $52 \%$ to $77 \%$ less than in oxidative conditions. Similar results were reported more recently by Sher et al. [36], who assessed the thermal and kinetics of diverse biomass fuels to provide valuable information for the power generation industry.

Yuzbasi et al. [35] compared the pyrolysis and combustion of co-firing biomass and coal with the individual behavior of each solid material. Regarding the pyrolysis, a similar trend was obtained up to $700{ }^{\circ} \mathrm{C}$. Furthermore, the oxygen levels shift the combustion profile to lower temperatures and an increase in the weight loss rate.

Shen et al. [32] investigated the thermal degradation of pine and birch and applied a new kinetic model, the distributed activation energy model (DAEM). DAEM was found not suitable to describe the thermal decomposition of biomass under oxidative conditions due to the capacity of oxygen to accelerate the mass loss in the first stage and promote complex reactions in the second stage. Furthermore, some works analyzed the influence of the effect of the oxidative and non-oxidative environment through experiments with different oxygen concentrations [9,37-40]. 
Fang et al. [9] studied the effects of oxygen concentration on the mass loss rate and kinetics of pyrolysis and combustion of wood. The authors stated that the mass loss rates of wood under different oxygen concentrations were similar when the temperature was below $250{ }^{\circ} \mathrm{C}$. Furthermore, it was found that the activation energy varied linearly with oxygen concentration at the first stage. Moreno et al. [40] also studied the kinetics of wood wastes and solid wood in different conditions considering three or four reactions and depending on if the reaction occured under oxidative or nonoxidative conditions. In turn, Amutio et al. [39] proposed a kinetic model consisting of six simultaneous reactions.

Chouchene et al. [37] studied the effect of three different atmospheres with different oxygen content on the thermal degradation of solid waste. It was verified that pyrolysis under inert conditions takes place according to two different stages (drying and devolatilization), while under oxidative conditions, a third stage, char oxidation, occurs. On the other hand, Su et al. [38] analyzed the effect of oxygen content on the thermal degradation of pine, and similar results were obtained. The oxygen promoted the degradation of biomass and a third stage was observed.

As the previous literature has thrown light on the TGA at different conditions, only a few works have succeeded in analyzing thermal conversion and determining all the kinetic parameters of experiments covering the possibility of oxidative and non-oxidative conditions with different flow rates. Thus, the main goal of this work is to study in more detail the thermal degradation of pine wood particles using a simultaneous DSC-TGA instrument. In this regard, experiments were performed to analyze some of the main parameters that most influence the thermal conversion of pine wood. In this way, this study is performed using oxidative (dry air) and non-oxidative (argon) environments and five different gas flow rates. The fundamental knowledge gained from this analysis is essential for the proper understanding of practical conversion systems. For instance, the knowledge of the low heating rate experiments may help to prevent accidental fires, which sometimes occur in fuel handling units of typical power plants. In the future, this study could be very useful to help the combustion optimization regarding the efficiency of the conversion process.

\section{Materials and Methods}

\subsection{Material and Sample Preparation}

To begin with, $6 \mathrm{~mm}$ diameter wood pellets certified according to the European Standard 149612 and ENPlus ${ }^{\circledast}$ A1 were milled into dust using of a knife mill. Once milled, the ground dust was sorted in a sieving device with the vibration unit to separate the wood particles. Particles between 0.125 and $0.25 \mathrm{~mm}$ were selected to carry out the TGA experiments.

Before the experiments, a sample of this batch was collected to determine the moisture, volatile matter, ash, and fixed carbon content. This proximate analysis is performed in line with the respective standards for solid fuels characterization. Furthermore, another sample was collected to determine the chemical composition of the fuel. This elemental analysis was also performed according to specific standards, and the content of the different elements was measured by a LECO TruSpec CHN Macro and by a TruSpec CHNS Micro to determine carbon, hydrogen, nitrogen and sulphur. Oxygen content was obtained by difference. The proximate and elemental analysis of the samples are provided in Table 1 . The heating value was measured by a calorimeter, LECO AC500 instrument. The lower heating value was estimated as $17.10 \mathrm{MJ} / \mathrm{kg}$.

Table 1. Proximate and elemental analysis of pine wood particles.

\begin{tabular}{crcr}
\hline Proximate Analysis (wt.\%, As Received) & Ultimate Analysis (wt.\%, Dry Ash Free) \\
\hline Moisture & 6.90 & Carbon & 50.90 \\
Volatile matter & 77.80 & Hydrogen & 5.30 \\
Ash & 0.60 & Nitrogen & 1.55 \\
Fixed carbon & 14.70 & Sulphur & 0.03 \\
& & Oxygen & 42.22 \\
\hline
\end{tabular}




\subsection{Thermogravimentric Experiments}

A simultaneous thermogravimetric and calorimetric analyzer TA INSTRUMENTS SDT 2960 was used to carry out the TGA experiments and kinetic study of pine wood particles in an inert and oxidative atmosphere. Samples with around $6 \mathrm{mg}$ were used in each experiment and they were subjected to thermal decomposition from ambient temperature up to $750{ }^{\circ} \mathrm{C}$ at $10{ }^{\circ} \mathrm{C} / \mathrm{min}$. This low heating rate was applied to avoid transport effects and to ensure that reaction is temperature dependent only, and therefore, the experiments are performed in a pure kinetic regime [6]. These initial conditions were based on previous experiments that were performed to ensure there was no possible effect on mass and heat transfer during the biomass decomposition. Regarding the final temperature, experiments at higher temperatures, above $750{ }^{\circ} \mathrm{C}$, were performed and there were no significant differences in the final mass, which ensures that any temperature increase does not contribute for further weight loss of the sample [31]. Furthermore, in these experiments, different flow rates $(2,10,50,100$ and $150 \mathrm{~mL} / \mathrm{min}$ ) of argon (inert atmosphere) and air (oxidative atmosphere) were applied to study pyrolysis and the combustion process, respectively.

The weight of the sample, temperature, and heat flow parameters were measured and recorded along with the time and the linearly increased temperature. In this way, thermogravimetric (TG), derivative thermogravimetric (DTG) and heat flow curves were derived from the data. These profiles enable the identification of the different reaction stages and the key temperatures such as ignition $\left(T_{i g}\right)$, initial decomposition $\left(T_{i n}\right)$, peak $\left(T_{\max }\right)$ and burnout temperature $\left(T_{b}\right)$. $T_{\text {in }}$ is the temperature at which the mass loss rate reaches $1 \% / \mathrm{min}$ after the initial moisture loss peak in the DTG profile. $T_{\max }$ is defined as the temperature where the maximum reaction rate occurs. $T_{b}$ is identified when the last peak comes to the end and can be defined as the inflection point at the final stage. It is taken as the point immediately before reaction ceases when the rate of weight loss is down to 1\%/min [35]. Tig is obtained by applying the TG-DTG tangent methods [41].

Additionally, these experiments enable the identification of the combustion rate and the heat released at different temperatures and times. With this analysis, a full characterization of the pyrolysis and combustion behavior of pine wood samples is obtained, and a detailed comparison can be carried out to understand the influence of the atmosphere. The procedure and method followed in this study to the TGA data analysis is based on the previous work of the same research group and more details can be found in the work of Fraga et al. [31].

In addition to this information, to complete the comparison between the combustion and pyrolysis behavior, two combustibility indexes from the mass loss rate data can be determined to provide a more accurate measure of the reactivity of the pine wood particles: the ignition index $(D)$ and the combustion index (S). $D$ and $S$ are defined by Equations (1) and (2):

$$
\begin{gathered}
D=\frac{(d m / d t)_{\text {max }}}{t_{\text {max }} \cdot t_{i g}} \\
S=\frac{(d m / d t)_{\max } \cdot(d m / d t)_{a v g}}{T_{b} \cdot T_{i g}^{2}}
\end{gathered}
$$

where $(d m / d t)_{\max }$ and $(d m / d t)_{a v g}$ are the maximum and average mass loss rate (wt.\%/min), and $t_{\max }$ and $t_{i g}(\mathrm{~min})$ are the time correspondent to the maximum combustion rate and ignition, respectively.

These two indexes indicate the ignition performance, i.e., how fast the fuel is ignited, and a comprehensive characteristic of the fuel, as the higher its value the more significantly the samples are burned and faster char is burned out [42].

\subsection{Kinetics Analysis}

To understand and model the biomass combustion process in furnaces, knowledge of the biomass combustion kinetics is essential. Furthermore, this knowledge is also mandatory to design a proper operation of biomass combustion equipment [43]. However, due to differences in the chemical composition of different components that constitute biomass materials, biomass pyrolysis and 
combustion are considered complex processes [34]. Consequently, there are several models in the literature, but they are related to the way to better describe the devolatilization process. Some authors consider just one global reaction divided into three stages [44,45], while others consider two parallel reactions with three reaction stages. A good description of these and other models used in the literature to describe biomass devolatilization is provided by White et al. [4], Branca et al. [46] and Várhegyi [47]. However, the decomposition kinetics of solid biomass fuels, considering non-isothermal heating, is usually based on a single-step kinetic equation as expressed by Equation (3):

$$
\frac{d \alpha}{d T}=k \cdot f(\alpha) \cdot \frac{1}{\beta}
$$

where $T$ is the temperature $(\mathrm{K}) ; f(\alpha)$ is a function called the reaction model, which describes the dependence of the reaction model on the conversion rate $(\alpha) ; \beta$ is the heating rate $(\beta=d T / d t)$; and $k$ is the thermal dependence term that can be defined by the Arrhenius equation (Equation (4)):

$$
k=A \cdot \exp \left(\frac{-E}{R T}\right)
$$

where $E$ is the activation energy $(\mathrm{kJ} / \mathrm{mol}), R$ is the universal gas constant $(\mathrm{kJ} /(\mathrm{mol} \cdot \mathrm{K}))$, and $A$ is the pre-exponential factor $\left(\mathrm{min}^{-1}\right)$.

The conversion rate, $\alpha$, can be defined as a relation between the initial $\left(m_{0}\right)$, final $\left(m_{f}\right)$, and instantaneous $\left(m_{t}\right)$ sample mass. These data can be obtained from each thermogravimetric experiment and defined by Equation (5):

$$
\alpha=\frac{m_{o}-m_{t}}{m_{o}-m_{f}}
$$

Considering the reaction model as a first-order reaction, this function can be expressed as (1$\alpha$ ), and Equation (3) can be expressed as Equation (6):

$$
\frac{d \alpha}{(1-\alpha)}=\frac{A}{\beta} \cdot \exp \left(\frac{-E}{R T}\right) \cdot d T
$$

The left-hand side of Equation (6) is a function of the conversion rate and the right side is a function of the temperature. Integrating both sides of Equation (6), Equation (7) is obtained:

$$
\int_{0}^{\alpha} \frac{d \alpha}{(1-\alpha)}=\frac{A}{\beta} \cdot \int_{T_{0}}^{T} \exp \left(\frac{-E}{R T}\right) \cdot d T
$$

Equation (7) has no exact solution, and there are two main mathematical approaches to solve this equation and obtain the kinetics data from the thermogravimetric analysis: (1) model-free methods (isoconversional) and (2) model-based methods [48]. The Coats-Redfern method, a modelbased method, has been extensively applied to model the kinetics of biomass pyrolysis and combustion since it is considered more appropriate for calculation of the kinetic parameters $[9,26-28,41,44,49-51]$. For this reason, this approach was employed in this work to study pine wood kinetics in oxidative and non-oxidative atmospheres. According to this method, an asymptotic series expansion to approximate the exponential integral is used [52], and considering a first order reaction model, $E$ and $A$ can be calculated by the logarithmic Equation (8):

$$
\ln \left[-\frac{\ln (1-\alpha)}{T^{2}}\right]=\ln \left(\frac{A R}{\beta E} \cdot\left(1-\frac{2 R T}{E}\right)\right)-\left(\frac{E}{R T}\right)
$$

Considering that the term $2 R T / E$ is much lower than one, this term can be ignored and Equation (8) can be reduced to Equation (9): 


$$
\ln \left[-\frac{\ln (1-\alpha)}{T^{2}}\right]=\ln \left(\frac{A R}{\beta E}\right)-\left(\frac{E}{R T}\right)
$$

If a plot of the term in the left hand side of Equation (9) versus $1 / T$ is made, $E$ and $A$ can be obtained from the slope $-E / R$ interception of $\ln (A R / \beta E)$, respectively.

This method can be applied to individual reactions. For instance, in biomass combustion, there are three individual reactions associated to drying, devolatilzaion and char combustion. Therefore, this method can be applied to the second stage (between $T_{\text {in }}$ and the temperature between the 2nd and 3rd peak), where the release and combustion of volatile matter occurs, and to the third stage (the temperature between the 2nd and 3rd peak and $\left.T_{b}\right)$, which is the char combustion and overall range (between $T_{\text {in }}$ and $T_{b}$ ).

\section{Results and Discussion}

\subsection{Thermal Decomposition Analysis}

The TGA experiments, as mentioned before, were performed with different atmospheres to study their influence on the thermal decomposition as a function of the flow rate. This is one of the most significant factors in the thermal decomposition of pine wood particles since in industrial furnaces, ambient oxygen concentration varies through time, which means that the reaction will change from pyrolysis to combustion. In this way, to analyze and compare both thermochemical conversion processes, Figure 1a,b present the TG and DTG curve, respectively. From Figure 1a, it is possible to observe that in the last combustion stage, when the temperature is higher than approximately $350{ }^{\circ} \mathrm{C}$, different TG and DTG curves as a function of different atmospheres were obtained. According to these figures, thermal decomposition under oxidative atmosphere (TG and DTG curves with dashed lines) occurs in three different stages: drying of the sample, devolatilization and finally the oxidation of the remaining char. However, when the inert atmosphere was applied (solid lines), only the first two stages took place. After the drying step, the second stage occurs between around $200^{\circ} \mathrm{C}$ and ends at approximately $400{ }^{\circ} \mathrm{C}$ depending on the flow rate. Above the last temperature, mass loss continues at a slower rate, and this process is associated with the slow degradation of lignin [37]. Furthermore, as can be observed in Figure 1b, the oxygen that is present in the oxidative atmosphere affects the maximum value of DTG curves, increasing its value, which is $15 \%$ higher than in an inert atmosphere, and decreasing the time needed to complete the reaction. Additionally, the maximum values of DTG curves were shifted to a lower temperature when compared to the maximum values obtained with the inert atmosphere.

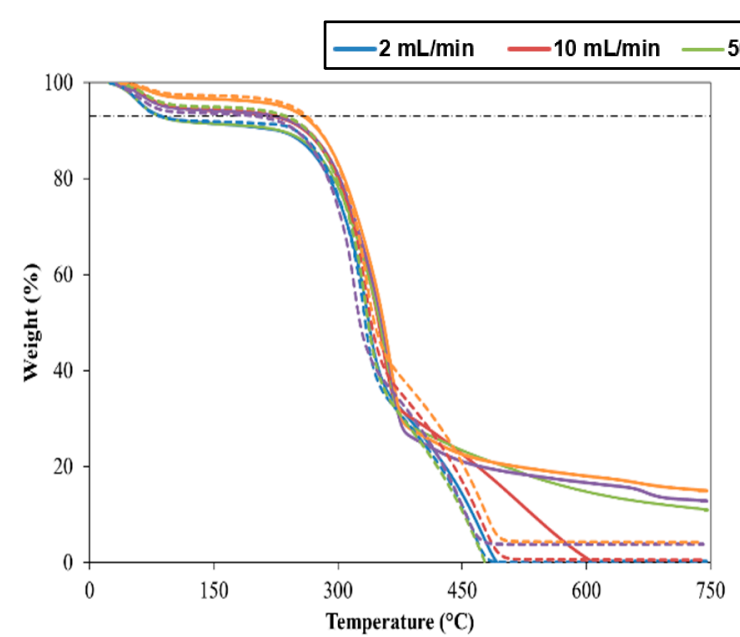

(a)

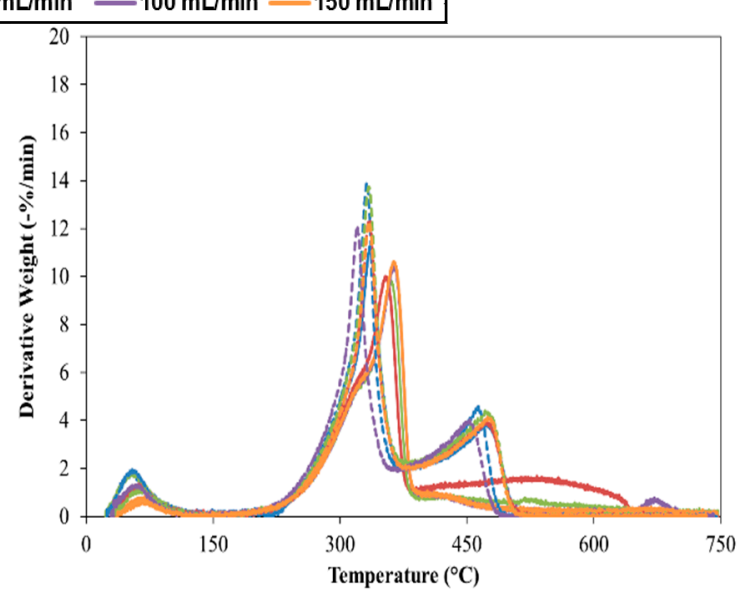

(b)

Figure 1. Thermogravimetric (TG) (a), and derivative thermogravimetric (DTG) (b) profiles for the different atmospheres and different flow rates; Air atmosphere-dashed line; Argon-continuous line. 
This can also be observed through the analysis of the temperature where the maximum reaction rate occurs $\left(T_{\max }\right)$. Figure 2 presents the variation of $T_{\max }$ and $T_{b}$, and it is possible to observe that experiments with oxidative atmosphere lose mass faster at lower temperatures when compared with experiments with inert atmospheres. This is a consequence of the presence of the oxygen that enhances the degradation of the pine due to the appearance of gas-phase reactions between the volatiles released and oxygen. Consequently, the oxygen promotes the oxidation of the remaining material, char, from the previous reaction and promotes its combustion extending the mass loss when compared with experiments with an inert atmosphere. This is the reason why in Figure 2, $T_{b}$ is higher in experiments with air. Despite this, it is also important to point out that in the experiment with 2 and $10 \mathrm{~mL} / \mathrm{min}$ of argon, similar behavior to the TG curves with the oxidative atmosphere was witnessed. This means that in experiments with low flow rates, independently of the atmosphere, the reaction is only temperature dependent and that similar mass loss behavior is obtained. However, as the inert gas flux is increased, the reaction was reduced, and lower $T_{b}$ was obtained. In the experiments with air, only minimum effects were observed on the thermograms at higher flow rates.

Regarding the other characteristic temperatures, $T_{\text {in }}$ was not significantly affected by the atmosphere, but experiments with air presented $T_{i g}$ lower around $10{ }^{\circ} \mathrm{C}$, and therefore, oxidative environment enhances the ignition of pine and leads to faster weight loss.

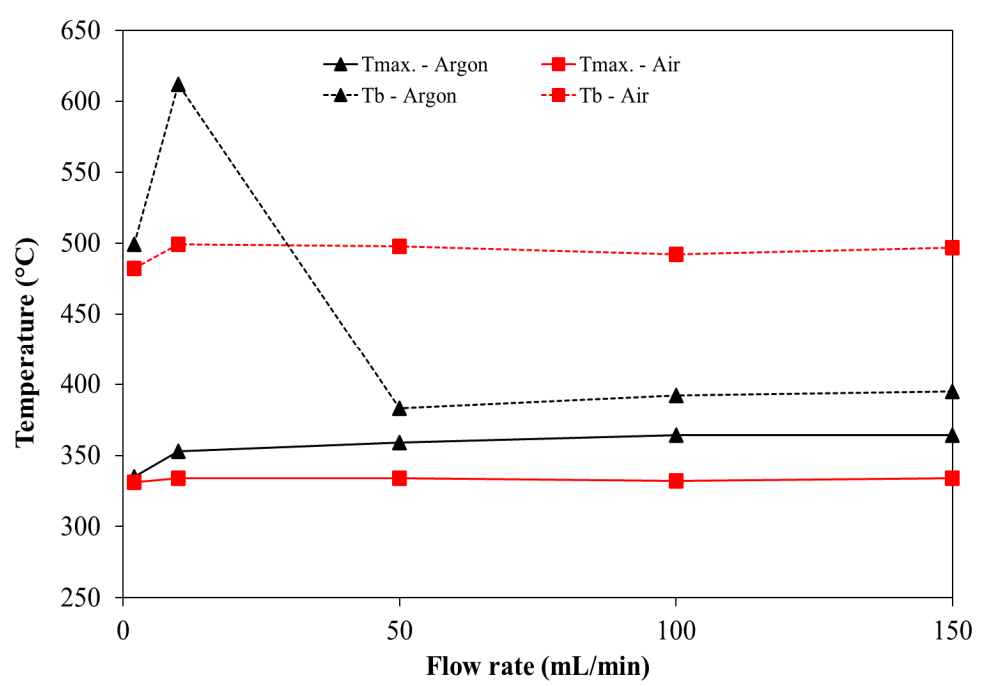

Figure 2. Peak and burnout temperature variation as a function of the atmosphere and flow rate.

In order to outline the differences between pyrolysis and combustion of pine, Figure 3 presents the maximum heat released (MHR) during the experiments and the maximum combustion rate (MCR) at the second stage under different gas flow rates. As evident from DTG curves, the average rate of char combustion is approximately 5 times higher with oxidative atmospheres when the flow rate was higher than $10 \mathrm{~mL} / \mathrm{min}$. Regarding the maximum heat released, significant differences were observed as the gas flow rate was increased.

As the oxygen reaches the surface of the particles after the volatiles released, a heterogenous reaction takes place and more energy and mass loss occurs. In the experiments with the inert atmosphere, this phenomenon does not occur, and therefore, the remaining mass (RM) and heat released (HR) are higher than in experiments with the oxidative atmosphere. This fact can be observed in Figure 4. Furthermore, an interesting point is that increasing the gas flow rate means that the differences between inert and oxidative atmospheres are more evident. The heat released in oxidative experiments reaches levels 3.44 times higher than in an inert atmosphere. 


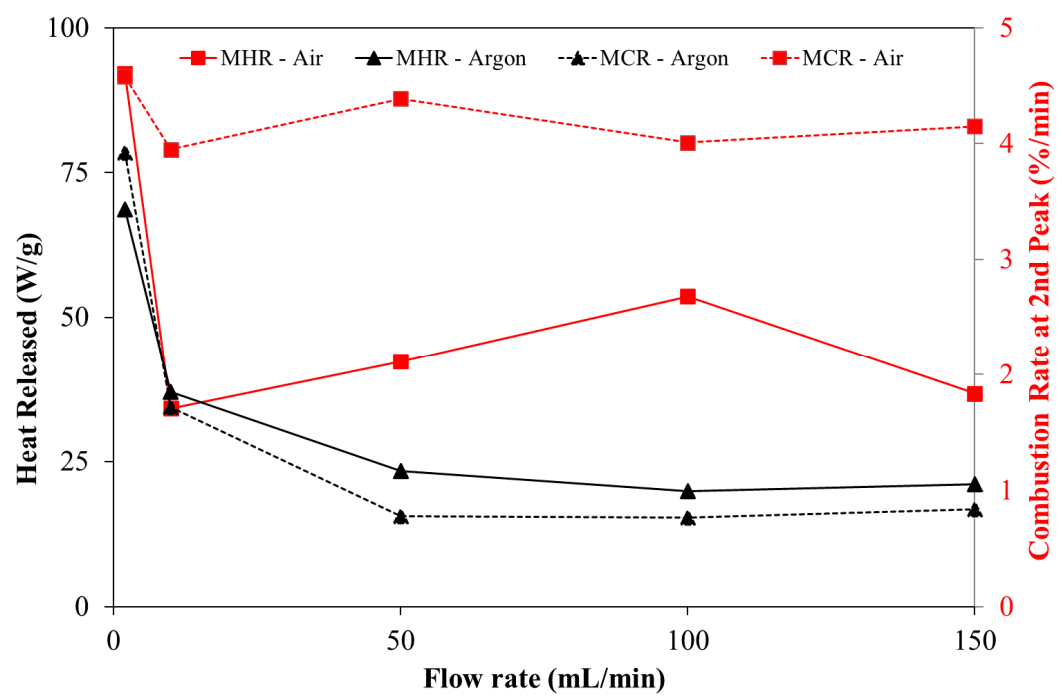

Figure 3. Maximum heat released and maximum combustion rate at the second combustion stage combustion indexes of pine wood particles at different atmospheres and flow rates.

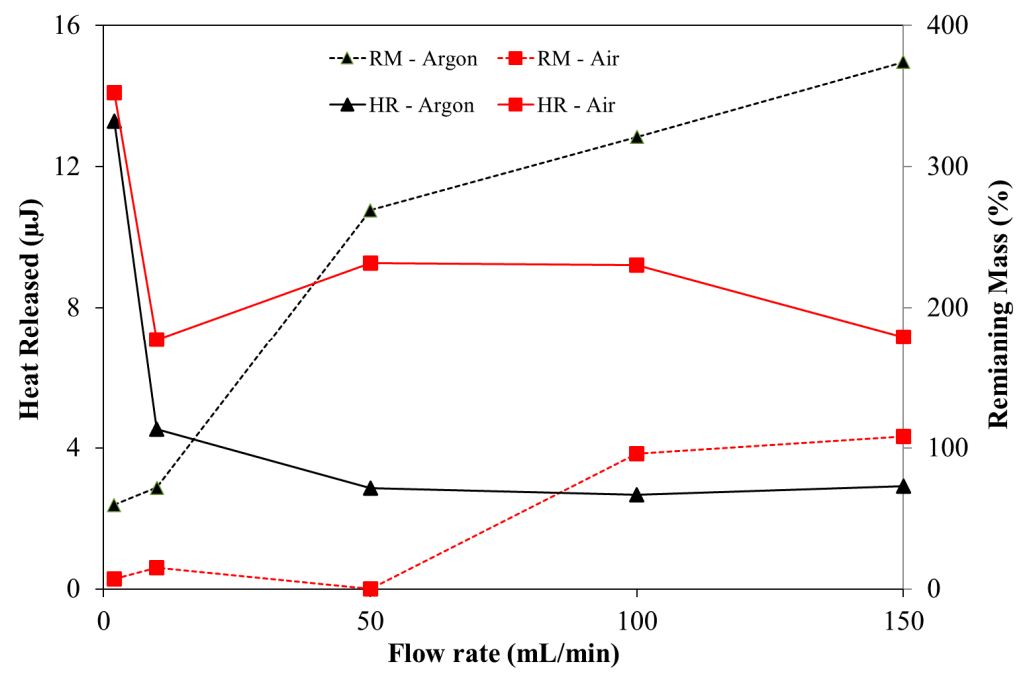

Figure 4. The heat released and remaining mass indexes of pine wood particles at different atmospheres and flow rates.

Following the procedure previously described, $D$ and $S$ indexes are presented in Figure 5 for different flow rates in both atmospheres. The results show that the $D$ index is correlated with the $T_{i g}$, and therefore, higher $D$ were observed when a better ignition performance was obtained. Consequently, as $T_{i g}$ increases with the flow rate, $D$ decreases at higher flow rates. Furthermore, the ignition with air atmosphere is enhanced, and $D$ presents higher values which means that pine wood particles are ignited faster than with inert atmosphere.

$S$ also follows a similar trend to the $D$ index. However, $S$ values obtained from experiments with the oxidative atmosphere present even higher values than those obtained from an inert atmosphere. On average, its value is 1.7 times higher, which reinforces the more vigorous way that the samples are burned and how char is burned out faster in the experiments with air. An important aspect that should be pointed out is that with $50 \mathrm{~mL} / \mathrm{min}$ air flow rate, the index $S$ presents the highest value, which means that the most efficient general combustion performance is obtained to this flow rate. Therefore, the global oxidation reaction took place close to the stoichiometric conditions, and with the other values the combustion occurred in an excess of comburent and with a lack of stoichiometric comburent. 


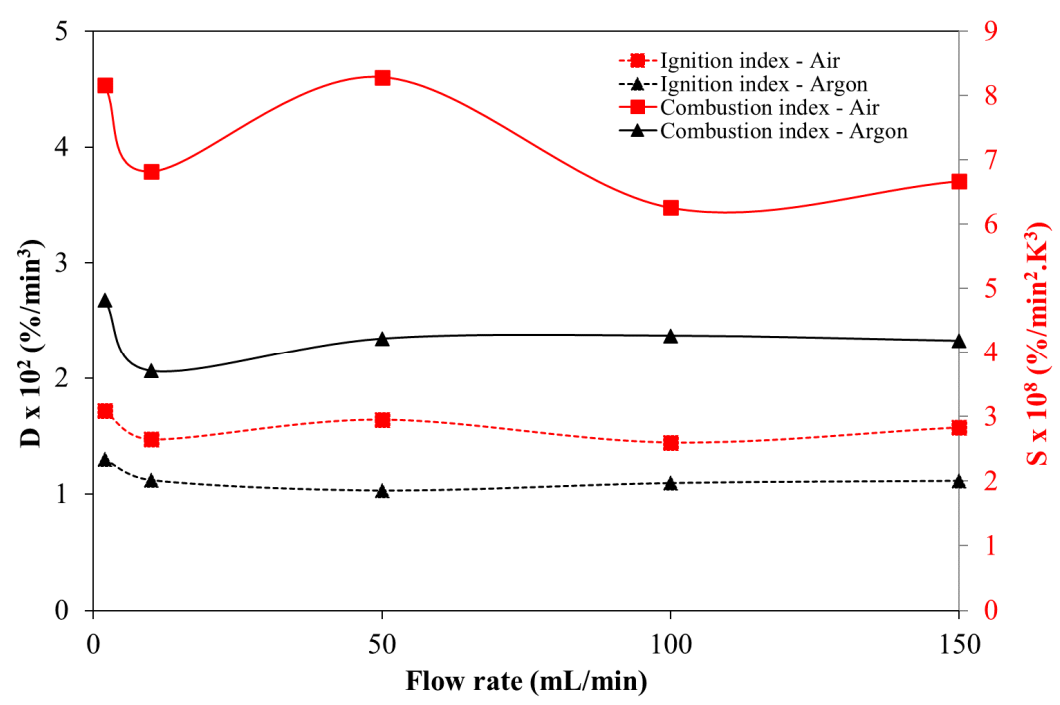

Figure 5. Combustion indexes of pine wood particles.

\subsection{Kinetics Analysis}

A kinetics analysis of the biomass pyrolysis and combustion using different flow rates was performed. The kinetic parameters of the second and third stage of both biomass pyrolysis and the combustion process were determined based on the first-order Coats-Redfern method. For each stage, a linear regression curve was determined in order to obtain the first-order equation that will allow determining the kinetic parameters.

The dependence of the activation energy on the atmosphere was significant, mainly in the third stage, and it is illustrated in Figure 6. It can be observed that the activation energy in the second stage from the inert atmosphere is lower than the values from oxidative experiments. Although the differences are not substantially different, this means that the reaction of the volatiles released, and combustion is less reactive than the pyrolysis.

Regarding the last combustion stage, a slower reactivity was found since higher activation energy values than in the second stage were obtained. Similar findings were obtained by GarciaMaraver et al. [36] and Álvarez et al. [33]. However, for this third combustion stage, there was no general trend of the heating rate effect. For instance, for lower flow rates the activation energy value was higher for inert atmospheres, while for gas flow rates higher than $10 \mathrm{~mL} / \mathrm{min}$, the opposite effect was obtained. This means that to higher flow rates $(>50 \mathrm{~mL} / \mathrm{min})$, lower reactivity is obtained for the char degradation under an inert atmosphere.

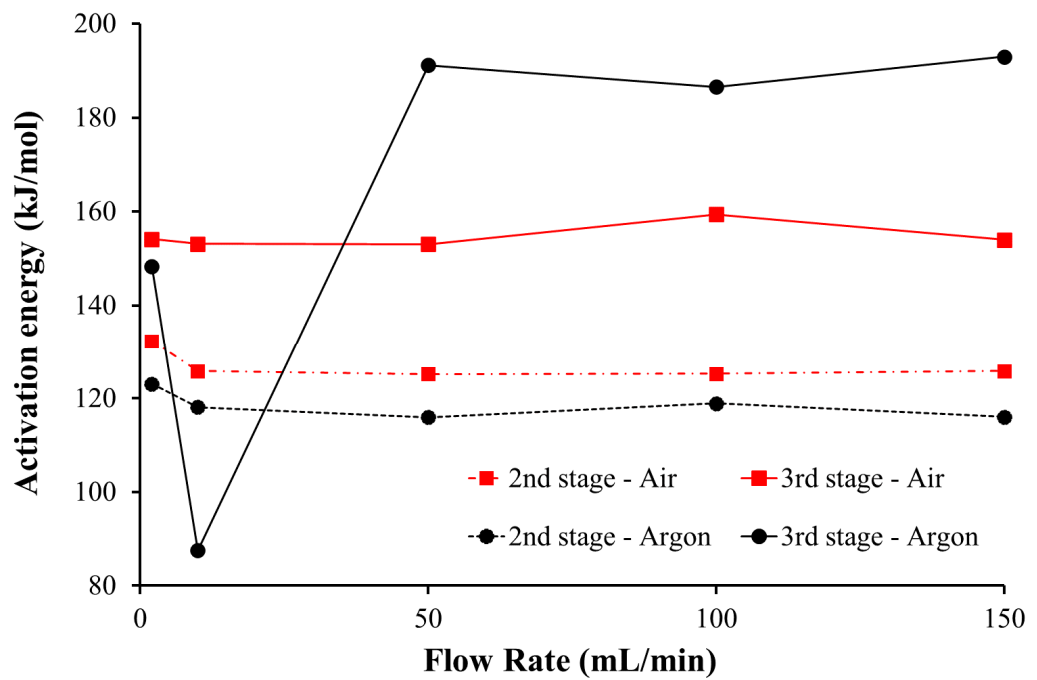

Figure 6. Estimated activation energy as a function of the flow rate. 
Furthermore, Table 2 presents the temperature range, pre-exponential factor, and correlation coefficient obtained from the Coats-Redfern method for each thermal degradation stage. The correlation coefficient $\left(\mathrm{R}^{2}\right)$ is considerably high for all the experiments carried out, and consequently, the first-order kinetic model can be considered feasible since revealed to fit well to the results $\left(\mathrm{R}^{2}>\right.$ 0.90). However, in the char thermal decomposition stage, the correlation coefficient presented a lower value, which can be related to complex reactions that take place and the first-order reaction presents some difficulties in fitting to the results. Regarding the pre-exponential factor for both second and third stages, higher values in the third stage were recorded.

Table 2. Temperature intervals, correlation coefficient and pre-exponential factor for each stage of combustion of all particles studied under different air flow rates.

\begin{tabular}{cccccccc}
\hline \multirow{2}{*}{ Atmosphere } & \multirow{2}{*}{ Flow Rate $(\mathbf{m L} / \mathbf{m i n})$} & \multicolumn{3}{c}{ 2nd Stage } & \multicolumn{3}{c}{ 3rd Stage } \\
\cline { 2 - 7 } & & $\mathbf{T}\left({ }^{\circ} \mathbf{C}\right)$ & $A\left(\mathbf{m i n}^{-1}\right)$ & $\mathbf{R}^{2}$ & $\boldsymbol{T}\left({ }^{\circ} \mathbf{C}\right)$ & $A\left(\mathbf{m i n}^{-1}\right)$ & $\mathbf{R}^{2}$ \\
\hline \multirow{4}{*}{ Air } & 2 & $247-370$ & $3.75 \times 10^{12}$ & 0.960 & $370-482$ & $1.72 \times 10^{12}$ & 0.920 \\
& 10 & $250-380$ & $7.38 \times 10^{11}$ & 0.957 & $380-499$ & $9.03 \times 10^{11}$ & 0.924 \\
& 50 & $248-380$ & $6.52 \times 10^{11}$ & 0.958 & $380-498$ & $8.82 \times 10^{11}$ & 0.923 \\
& 100 & $250-380$ & $6.88 \times 10^{11}$ & 0.954 & $380-492$ & $2.96 \times 10^{12}$ & 0.925 \\
\multirow{3}{*}{ Argon } & 150 & $250-380$ & $7.38 \times 10^{11}$ & 0.957 & $380-497$ & $1.04 \times 10^{12}$ & 0.923 \\
& 2 & $248-378$ & $4.50 \times 10^{11}$ & 0.956 & $378-499$ & $3.99 \times 10^{11}$ & 0.920 \\
& 10 & $249-390$ & $1.16 \times 10^{11}$ & 0.957 & $390-612$ & $2.39 \times 10^{6}$ & 0.901 \\
& 50 & $242-380$ & $1.13 \times 10^{11}$ & 0.955 & $380-474$ & $1.16 \times 10^{15}$ & 0.926 \\
& 100 & $239-370$ & $2.72 \times 10^{11}$ & 0.957 & $370-456$ & $7.95 \times 10^{14}$ & 0.896 \\
& 150 & $242-380$ & $1.15 \times 10^{11}$ & 0.954 & $380-473$ & $1.61 \times 10^{15}$ & 0.926 \\
\hline
\end{tabular}

\section{Conclusions}

The present work focuses on the analysis of the thermal conversion of pine wood and kinetics under oxidative and non-oxidative environments at a low heating rate. From this perspective, a nonisothermal thermogravimetric experiment (TGA), a well-known method, was performed to investigate and understand the differences between pyrolysis and combustion at the particle level with different gas flow rates. In this research work, the findings are summarized as follows:

- It was observed that the thermal decomposition of pine wood particles varied from three to two stages in the presence of an oxidative or inert atmosphere respectively;

- The presence of oxygen changes the mass loss curve mainly at high temperature, around $350{ }^{\circ} \mathrm{C}$, where char reacts with oxygen and promotes the degradation of the remaining mass. Therefore, the gas-phase reactions enhance the thermal conversion when compared with experiments with an inert atmosphere;

- The maximum value of DTG curves from experiments with the oxidative atmosphere is $15 \%$ higher than in an inert atmosphere, and the time to complete the reaction is also higher since the char mass loss continues at a slower rate and this process is associated with the slow degradation of lignin. Additionally, the maximum values of DTG curves were shifted to a lower temperature when compared to the maximum values obtained with the inert atmosphere;

- The average char combustion rate is approximately 5 times higher with the oxidative atmosphere when the flow rate was higher than $10 \mathrm{~mL} / \mathrm{min}$;

- Regarding the maximum heat released, significant differences were observed as the gas flow rate was increased. However, the heat released in oxidative experiments is up to 3.44 times higher than in an inert atmosphere;

- As a result of the presence of the oxygen, $\mathrm{T}_{\max }$ is lower and $\mathrm{T}_{\mathrm{b}}$ is higher than experiments under an inert atmosphere. Regarding the other characteristic temperatures, Tin was not significantly affected by the atmosphere but, $\mathrm{T}_{\mathrm{ig}}$ is lower around $10{ }^{\circ} \mathrm{C}$ for the case where combustion takes place. Therefore, the oxidative environment enhances the ignition of pine and leads to faster weight loss; 
- The index $D$ presents higher values which means that pine wood particles are ignited faster than under inert atmosphere. The comprehensive characteristic of the fuel defined by index $S$ also presents higher values for the case where the oxidative atmosphere was applied. On average, its value is 1.7 times higher, which reinforces the more vigorously way that the samples are burned and how char is burned out faster in the experiments with air;

- The kinetics analysis was carried out considering a first-order reaction to each thermal conversion stage and the Coats-Redfern method. Results revealed that the kinetic parameters are affected by the gaseous atmosphere;

- Higher activation energies and, consequently, lower reactivity was obtained under the oxidative atmosphere for the second stage and under the inert atmosphere for the third thermal conversion stage. Although, in the second stage, the differences are not substantially different, this means that the reaction of the volatiles released and combustion are less reactive than the pyrolysis. The opposite trend happens in the last conversion stage at higher flow rates.

Author Contributions: Conceptualization, L.G.F., J.S., J.T., and M.F.; methodology, L.G.F., J.S., J.T., and D.S.; investigation, L.G.F., J.S.; writing-original draft preparation, L.G.F., J.S., J.T., and S.T.; writing-review and editing, L.G.F., J.S., J.T., and S.T.; supervision, J.T., M.F., and D.S. All authors have read and agreed to the published version of the manuscript.

Funding: This work was supported by Portuguese Foundation for Science and Technology (FCT) within the R\&D Units Project Scope UIDB/00319/2020 (ALGORITMI), R\&D Units Project Scope UIDP/04077/2020 (MEtRICs) and R\&D Units Project Scope UIDB/04436/2020 (CMEMS).

Acknowledgements: The second author would like to express his gratitude for the support given by FCT through the PhD Grant SFRH/BD/130588/2017.

Conflicts of Interest: The authors declare no conflict of interest.

\section{Nomenclature}

\begin{tabular}{|c|c|}
\hline$A$ & pre-exponential factor, $\min ^{-1}$ \\
\hline$D$ & ignition index, $\% / \mathrm{min}^{3}$ \\
\hline \multicolumn{2}{|c|}{ DTG derivative thermogravimetric } \\
\hline$E$ & activation energy, $\mathrm{kJ} / \mathrm{mol}$ \\
\hline$H R$ & heat released \\
\hline$k$ & rate of the chemical reaction, $\mathrm{min}^{-1}$ \\
\hline$m$ & mass, mg \\
\hline \multicolumn{2}{|c|}{ MCRmaximum combustion rate } \\
\hline MHR & maximum heat released \\
\hline$R$ & universal gas contant, $\mathrm{kJ} /(\mathrm{mol} . \mathrm{K})$ \\
\hline$R M$ & remaining mass \\
\hline$S$ & combustion index, $\% /\left(\min ^{2} \cdot \mathrm{K}^{3}\right)$ \\
\hline$t$ & time, $\min ^{-1}$ \\
\hline$T$ & temperature, ${ }^{\circ} \mathrm{C}$ \\
\hline TG & thermogravimetric \\
\hline TGA & thermogravimetric analysis \\
\hline \multicolumn{2}{|c|}{ Greek symbols } \\
\hline$\alpha$ & conversion rate, - \\
\hline$\beta$ & heating rate, ${ }^{\circ} \mathrm{C} / \mathrm{min}$ \\
\hline \multicolumn{2}{|c|}{ Subscripts and superscripts } \\
\hline 0 & initial \\
\hline$a$ & air \\
\hline $\operatorname{avg}$ & average \\
\hline$b$ & burnout \\
\hline$f$ & final \\
\hline$i g$ & ignition \\
\hline in & initial decomposition \\
\hline $\max$ & maximum \\
\hline$t$ & time \\
\hline
\end{tabular}




\section{References}

1. Mandova, H.; Leduc, S.; Wang, C.; Wetterlund, E.; Patrizio, P.; Gale, W.; Kraxner, F. Possibilities for $\mathrm{CO}_{2}$ emission reduction using biomass in European integrated steel plants. Biomass Bioenergy 2018, 115, 231243, doi:10.1016/J.BIOMBIOE.2018.04.021.

2. Malico, I.; Nepomuceno Pereira, R.; Gonçalves, A.C.; Sousa, A.M.O. Current status and future perspectives for energy production from solid biomass in the European industry. Renew. Sustain. Energy Rev. 2019, 112, 960-977, doi:10.1016/J.RSER.2019.06.022.

3. Nussbaumer, T. Combustion and Co-combustion of Biomass: Fundamentals, Technologies, and Primary Measures for Emission Reduction. Energy Fuels 2003, 17, 1510-1521, doi:10.1021/ef030031q.

4. White, J.E.; Catallo, W.J.; Legendre, B.L. Biomass pyrolysis kinetics: A comparative critical review with relevant agricultural residue case studies. J. Anal. Appl. Pyrolysis 2011, 91, 1-33, doi:10.1016/J.JAAP.2011.01.004.

5. Cai, J.; Xu, D.; Dong, Z.; Yu, X.; Yang, Y.; Banks, S.W.; Bridgwater, A.V. Processing thermogravimetric analysis data for isoconversional kinetic analysis of lignocellulosic biomass pyrolysis: Case study of corn stalk. Renew. Sustain. Energy Rev. 2018, 82, 2705-2715, doi:10.1016/J.RSER.2017.09.113.

6. Anca-Couce, A.; Tsekos, C.; Retschitzegger, S.; Zimbardi, F.; Funke, A.; Banks, S.; Kraia, T.; Marques, P.; Scharler, R.; de Jong, W.; et al. Biomass pyrolysis TGA assessment with an international round robin. Fuel 2020, 276, 118002, doi:10.1016/j.fuel.2020.118002.

7. Williams, P.T.; Besler, S. The influence of temperature and heating rate on the slow pyrolysis of biomass. Renew. Energy 1996, 7, 233-250, doi:10.1016/0960-1481(96)00006-7.

8. Kleinhans, U.; Wieland, C.; Frandsen, F.J.; Spliethoff, H. Ash formation and deposition in coal and biomass fired combustion systems: Progress and challenges in the field of ash particle sticking and rebound behavior. Prog. Energy Combust. Sci. 2018, 68, 65-168, doi:10.1016/J.PECS.2018.02.001.

9. Fang, M.X.; Shen, D.K.; Li, Y.X.; Yu, C.J.; Luo, Z.Y.; Cen, K.F. Kinetic study on pyrolysis and combustion of wood under different oxygen concentrations by using TG-FTIR analysis. J. Anal. Appl. Pyrolysis 2006, 77, 22-27, doi:10.1016/J.JAAP.2005.12.010.

10. Yin, C.; Rosendahl, L.A.; Kær, S.K. Grate-firing of biomass for heat and power production. Prog. Energy Combust. Sci. 2008, 34, 725-754, doi:10.1016/j.pecs.2008.05.002.

11. Grønli, M.G.; Várhegyi, G.; Di Blasi, C. Thermogravimetric Analysis and Devolatilization Kinetics of Wood. Ind. Eng. Chem. Res. 2002, 41, 4201-4208, doi:10.1021/ie0201157.

12. Saddawi, A.; Jones, J.M.; Williams, A.; Wójtowicz, M.A. Kinetics of the Thermal Decomposition of Biomass. Energy Fuels 2010, 24, 1274-1282, doi:10.1021/ef900933k.

13. Wadhwani, R.; Sutherland, D.; Moinuddin, K.A.M.; Joseph, P. Kinetics of pyrolysis of litter materials from pine and eucalyptus forests. J. Therm. Anal. Calorim. 2017, 130, 2035-2046, doi:10.1007/s10973-017-6512-0.

14. Xiao, R.; Yang, W.; Cong, X.; Dong, K.; Xu, J.; Wang, D.; Yang, X. Thermogravimetric analysis and reaction kinetics of lignocellulosic biomass pyrolysis. Energy 2020, 201, 117537, doi:10.1016/j.energy.2020.117537.

15. Alvarado Flores, J.J.; Rutiaga Quiñones, J.G.; Ávalos Rodríguez, M.L.; Alcaraz Vera, J.V.; Espino Valencia, J.; Guevara Martínez, S.J.; Márquez Montesino, F.; Alfaro Rosas, A. Thermal Degradation Kinetics and FTIR Analysis on the Pyrolysis of Pinus pseudostrobus, Pinus leiophylla and Pinus montezumae as Forest Waste in Western Mexico. Energies 2020, 13, 969, doi:10.3390/en13040969.

16. Darvell, L.I.; Jones, J.M.; Gudka, B.; Baxter, X.C.; Saddawi, A.; Williams, A.; Malmgren, A. Combustion properties of some power station biomass fuels. Fuel 2010, 89, 2881-2890, doi:10.1016/J.FUEL.2010.03.003.

17. Kim, S.-S.; Kim, J.; Park, Y.-H.; Park, Y.-K. Pyrolysis kinetics and decomposition characteristics of pine trees. Bioresour. Technol. 2010, 101, 9797-9802, doi:10.1016/J.BIORTECH.2010.07.094.

18. Mani, T.; Murugan, P.; Abedi, J.; Mahinpey, N. Pyrolysis of wheat straw in a thermogravimetric analyzer: Effect of particle size and heating rate on devolatilization and estimation of global kinetics. Chem. Eng. Res. Des. 2010, 88, 952-958, doi:10.1016/J.CHERD.2010.02.008.

19. Seo, D.K.; Park, S.S.; Hwang, J.; Yu, T.-U. Study of the pyrolysis of biomass using thermo-gravimetric analysis (TGA) and concentration measurements of the evolved species. J. Anal. Appl. Pyrolysis 2010, 89, 66-73, doi:10.1016/J.JAAP.2010.05.008.

20. Slopiecka, K.; Bartocci, P.; Fantozzi, F. Thermogravimetric analysis and kinetic study of poplar wood pyrolysis. Appl. Energy 2012, 97, 491-497, doi:10.1016/J.APENERGY.2011.12.056.

21. Chen, D.; Zheng, Y.; Zhu, X. In-depth investigation on the pyrolysis kinetics of raw biomass. Part I: Kinetic analysis for the drying and devolatilization stages. Bioresour. Technol. 2013, 131, 40-46, doi:10.1016/J.BIORTECH.2012.12.136. 
22. Parthasarathy, P.; Narayanan, K.S.; Arockiam, L. Study on kinetic parameters of different biomass samples using thermo-gravimetric analysis. Biomass Bioenergy 2013, 58, 58-66, doi:10.1016/J.BIOMBIOE.2013.08.004.

23. Saldarriaga, J.F.; Aguado, R.; Pablos, A.; Amutio, M.; Olazar, M.; Bilbao, J. Fast characterization of biomass fuels by thermogravimetric analysis (TGA). Fuel 2015, 140, 744-751, doi:10.1016/j.fuel.2014.10.024.

24. Di Blasi, C. Modeling chemical and physical processes of wood and biomass pyrolysis. Prog. Energy Combust. Sci. 2008, 34, 47-90, doi:10.1016/J.PECS.2006.12.001.

25. Bilbao, R.; Mastral, J.F.; Aldea, M.E.; Ceamanos, J. Kinetic study for the thermal decomposition of cellulose and pine sawdust in an air atmosphere. J. Anal. Appl. Pyrolysis 1997, 39, 53-64, doi:10.1016/S01652370(96)00957-6.

26. Shen, D.K.; Gu, S.; Luo, K.H.; Bridgwater, A.V.; Fang, M.X. Kinetic study on thermal decomposition of woods in oxidative environment. Fuel 2009, 88, 1024-1030, doi:10.1016/J.FUEL.2008.10.034.

27. Yorulmaz, S.Y.; Atimtay, A.T. Investigation of combustion kinetics of treated and untreated waste wood samples with thermogravimetric analysis. Fuel Process. Technol. 2009, 90, 939-946, doi:10.1016/j.fuproc.2009.02.010.

28. Garcia-Maraver, A.; Perez-Jimenez, J.A.; Serrano-Bernardo, F.; Zamorano, M. Determination and comparison of combustion kinetics parameters of agricultural biomass from olive trees. Renew. Energy 2015, 83, 897-904, doi:10.1016/J.RENENE.2015.05.049.

29. Ren, X.; Chen, J.; Li, G.; Wang, Y.; Lang, X.; Fan, S. Thermal oxidative degradation kinetics of agricultural residues using distributed activation energy model and global kinetic model. Bioresour. Technol. 2018, 261, 403-411, doi:10.1016/J.BIORTECH.2018.04.047.

30. Dhahak, A.; Bounaceur, R.; Le Dreff-Lorimier, C.; Schmidt, G.; Trouve, G.; Battin-Leclerc, F. Development of a detailed kinetic model for the combustion of biomass. Fuel 2019, 242, 756-774, doi:10.1016/J.FUEL.2019.01.093.

31. Fraga, L.G.; Silva, J.; Teixeira, S.; Soares, D.; Ferreira, M.; Teixeira, J. Influence of Operating Conditions on the Thermal Behavior and Kinetics of Pine Wood Particles using Thermogravimetric Analysis. Energies 2020, 13, 2756, doi:10.3390/en13112756.

32. Shen, D.K.; Gu, S.; Jin, B.; Fang, M.X. Thermal degradation mechanisms of wood under inert and oxidative environments using DAEM methods. Bioresour. Technol. 2011, 102, 2047-2052, doi:10.1016/J.BIORTECH.2010.09.081.

33. Anca-Couce, A.; Zobel, N.; Berger, A.; Behrendt, F. Smouldering of pine wood: Kinetics and reaction heats. Combust. Flame 2012, 159, 1708-1719, doi:10.1016/J.COMBUSTFLAME.2011.11.015.

34. Munir, S.; Daood, S.S.; Nimmo, W.; Cunliffe, A.M.; Gibbs, B.M. Thermal analysis and devolatilization kinetics of cotton stalk, sugar cane bagasse and shea meal under nitrogen and air atmospheres. Bioresour. Technol. 2009, 100, 1413-1418, doi:10.1016/J.BIORTECH.2008.07.065.

35. Yuzbasi, N.S.; Selçuk, N. Air and oxy-fuel combustion characteristics of biomass/lignite blends in TGAFTIR. Fuel Process. Technol. 2011, 92, 1101-1108, doi:10.1016/J.FUPROC.2011.01.005.

36. Sher, F.; Iqbal, S.Z.; Liu, H.; Imran, M.; Snape, C.E. Thermal and kinetic analysis of diverse biomass fuels under different reaction environment: A way forward to renewable energy sources. Energy Convers. Manag. 2020, 203, 112266, doi:10.1016/J.ENCONMAN.2019.112266.

37. Chouchene, A.; Jeguirim, M.; Khiari, B.; Zagrouba, F.; Trouvé, G. Thermal degradation of olive solid waste: Influence of particle size and oxygen concentration. Resour. Conserv. Recycl. 2010, 54, 271-277, doi:10.1016/j.resconrec.2009.04.010.

38. Su, Y.; Luo, Y.; Wu, W.; Zhang, Y.; Zhao, S. Characteristics of pine wood oxidative pyrolysis: Degradation behavior, carbon oxide production and heat properties. J. Anal. Appl. Pyrolysis 2012, 98, 137-143, doi:10.1016/J.JAAP.2012.07.005.

39. Amutio, M.; Lopez, G.; Aguado, R.; Artetxe, M.; Bilbao, J.; Olazar, M. Kinetic study of lignocellulosic biomass oxidative pyrolysis. Fuel 2012, 95, 305-311, doi:10.1016/J.FUEL.2011.10.008.

40. Moreno, A.I.; Font, R.; Conesa, J.A. Combustion of furniture wood waste and solid wood: Kinetic study and evolution of pollutants. Fuel 2017, 192, 169-177, doi:10.1016/J.FUEL.2016.12.022.

41. Magalhães, D.; Kazanç, F.; Riaza, J.; Erensoy, S.; Kabaklı, Ö.; Chalmers, H. Combustion of Turkish lignites and olive residue: Experiments and kinetic modelling. Fuel 2017, 203, 868-876, doi:10.1016/J.FUEL.2017.05.050.

42. Lin, Y.; Ma, X.; Ning, X.; Yu, Z. TGA-FTIR analysis of co-combustion characteristics of paper sludge and oil-palm solid wastes. Energy Convers. Manag. 2015, 89, 727-734, doi:10.1016/J.ENCONMAN.2014.10.042. 
43. Sanchez, M.E.; Otero, M.; Gómez, X.; Morán, A. Thermogravimetric kinetic analysis of the combustion of biowastes. Renew. Energy 2009, 34, 1622-1627, doi:10.1016/j.renene.2008.11.011.

44. Fang, X.; Jia, L.; Yin, L. A weighted average global process model based on two-stage kinetic scheme for biomass combustion. Biomass Bioenergy 2013, 48, 43-50, doi:10.1016/J.BIOMBIOE.2012.11.011.

45. Gangavati, P.B.; Safi, M.J.; Singh, A.; Prasad, B.; Mishra, I.M. Pyrolysis and thermal oxidation kinetics of sugar mill press mud. Thermochim. Acta 2005, 428, 63-70, doi:10.1016/j.tca.2004.09.026.

46. Branca, C.; Albano, A.; Di Blasi, C. Critical evaluation of global mechanisms of wood devolatilization. Thermochim. Acta 2005, 429, 133-141, doi:10.1016/J.TCA.2005.02.030.

47. Várhegyi, G. Aims and methods in non-isothermal reaction kinetics. J. Anal. Appl. Pyrolysis 2007, 79, 278288, doi:10.1016/J.JAAP.2007.01.007.

48. Garcia-Maraver, A.; Perez-Jimenez, J.A.; Serrano-Bernardo, F.; Zamorano, M. Determination and comparison of combustion kinetics parameters of agricultural biomass from olive trees. Renew. Energy 2015, 83, 897-904, doi:10.1016/j.renene.2015.05.049.

49. Álvarez, A.; Pizarro, C.; García, R.; Bueno, J.L.; Lavín, A.G. Determination of kinetic parameters for biomass combustion. Bioresour. Technol. 2016, 216, 36-43, doi:10.1016/J.BIORTECH.2016.05.039.

50. Yu, D.; Chen, M.; Wei, Y.; Niu, S.; Xue, F. An assessment on co-combustion characteristics of Chinese lignite and eucalyptus bark with TG-MS technique. Powder Technol. 2016, 294, 463-471, doi:10.1016/J.POWTEC.2016.03.016.

51. Mishra, R.K.; Mohanty, K. Pyrolysis kinetics and thermal behavior of waste sawdust biomass using thermogravimetric analysis. Bioresour. Technol. 2018, 251, 63-74, doi:10.1016/J.BIORTECH.2017.12.029.

52. Coats, A.W.; Redfern, J.P. Kinetic Parameters from Thermogravimetric Data. Nature 1964, 201, 68-69, doi:10.1038/201068a0.

Publisher's Note: MDPI stays neutral with regard to jurisdictional claims in published maps and institutional affiliations.

(C) 2020 by the authors. Licensee MDPI, Basel, Switzerland. This article is an open access article distributed under the terms and conditions of the Creative Commons Attribution (CC BY) license (http://creativecommons.org/licenses/by/4.0/). 